\title{
Internet Usage and Traditional Distribution Channels: The Moderating Effect of the Firm's Size in Jordan
}

\author{
Ghaith M. Al-Abdallah ${ }^{1}$, Khaldoon H. Al-Khawaldeh ${ }^{2} \&$ Anas Y. Al-Hadid ${ }^{1}$ \\ ${ }^{1}$ Department of Marketing, Faculty of Economics and Administrative Sciences, Applied Science University, \\ Jordan \\ ${ }^{2}$ Department of Business Administration, Faculty of Economics and Administrative Sciences, Applied Science \\ University, Jordan \\ Correspondence: Ghaith Mustafa Al-Abdallah, Department of Marketing, Faculty of Economics and \\ Administrative Sciences, Applied Science University, Amman, Jordan. E-mail: ghaith.abdallah@yahoo.com
}

Received: January 21, 2014

Accepted: February 7, 2014

Online Published: February 24, 2014

doi:10.5539/ibr.v7n3p81

URL: http://dx.doi.org/10.5539/ibr.v7n3p81

\begin{abstract}
Internet importance and effect is increasing in every part of daily life, especially in business where internet can provide some serious solutions for many issues, it can alter many traditional methods and procedures that would include distribution. Distribution channels are traditionally the organization, or set of organizations, responsible for delivering a product from the manufacturer to the end-users, Internet has affected traditional distribution channels in developed countries and markets, in fact; internet itself can be viewed as a new distribution channel. Accordingly, this study aims at identifying the effect of internet usage on the traditional distribution channels in Jordanian private commercial firms in terms of creating new direct online sales channel and reducing the numbers of intermediaries. The study also examines the moderating effect of firm's size on the original relation between internet usage and traditional distribution channels. In order to achieve these objectives, two main hypotheses were formed based on the literature review. A regulated research methodology was applied to test the hypotheses over a proportional systematic random sample from large, medium, and small private commercial firms in Jordan. A questionnaire was constructed and distributed to top and middle management of private commercial firms in Jordan. 904 screened and filtered questionnaires were processed using SPSS. The results of the statistical analysis were demonstrated, showing that internet has a partial effect on traditional distribution channels, the effect is limited to creating new direct online channel, and even this effect is weak, and got even weaker as the firms size got smaller.
\end{abstract}

Keywords: internet usage, traditional distribution channels, firm's size, commercial sector, Jordan

\section{Introduction}

The rapid and continuing growth of internet and the World Wide Web (www) has been noticed and examined by many researchers (Cockburn \& Wilson, 1996; Aldridge et al., 1997; Griffiths, 1999; Coffman \& Odlyzko, 2001) and many theorists and professionals predicted that Internet will change the way we do business (Nath et al., 1998; Wen et al., 2001; Yoffie, 2010). Internet growth is expected to keep increasing as the number of internet users and online shopper is increasing daily. By the end of 2012, around 2.4 billion internet users were online compared to only 424 million internet users in 2000, making internet the biggest media of all time (internet world stats, 2012).

Internet can be defined in a simple way as a global network of interconnected networks (Strauss \& Frost, 2012). Internet now is one of the most efficient medium to do business. In developed countries, internet proved to be very helpful to firms, internet usage offers great chance for firms to compete worldwide efficiently (Scupola, 2002). Since that is the case in developed countries, one would wonder whether the same can be found in developing countries (such as Jordan). Therefore examining the effect of internet usage on different businesses and marketing activities and practices in developing countries will provide better understanding of the actual situation of internet usage worldwide.

The scope of internet usage in business and marketing is very wide, ranging from providing simple information to full electronic transaction. No matter what stage of internet usage the firm adopts, it should have a website and 
active e-mail address. In this study the researchers focus on examining the internet usage effect on traditional distribution channels directly and examine the moderating effect of the firm's size on the direct relation between internet usage and traditional distribution channels for Jordanian commercial firms that have active websites and valid e-mail addresses.

Bucklin (1966) defined the role of distribution channels "to provide a firm the accomplishment of the task of delivering the product at a right time, place, and quantity at a minimum cost" Till these days, the aim of distribution channels remained the same even with the emerging of new channels such as the internet. Ever since it was opened to civilian use, internet was recognized as a distribution channel, according to Morgansky (1997) internet is a new distribution channel that should reduce the cost for firms and consequently, for customers, indicating the solid relation between internet usage and traditional distribution channels. Melewar and Smith (2003) considered internet as a "global channel" in which firms can convey complete commercial offerings.

\section{Conceptual Framework}

\subsection{Distribution Channels}

Distribution channels can be described as the organization (or set of organizations) participating in the procedure of making a product or service available to be used by individual or business user (Dent, 2008).

Distribution could be direct, from the manufacturer to the end-user, or it could go through a series of intermediaries; each passing the product to the next organization, before it finally reaches the end-user. Every component in the series will have their own particular needs, which the manufacturer must consider, along with the need of end-users (William et al., 2008). Distribution channels are composed of independent dealers with individual preferences, which means that the manufacturer will always depends on a set of dealers to deliver products to the selling point. Based on this, those dealers might concentrate their actions and activities on shortterm profits, ignoring activities with no immediate gain; which could affect the manufacturer objectives in a negative way (Anderson, 1985). This situation could only be more complicated when the manufacturer has no direct relationships with end-users and therefore feels forced to keep dealing with dealers and intermediaries in order to reach consumers. Internet usage could be the solution for this issue in many sectors, products, and services. However, things are not that easy, as distribution channels have many functions, and not all can be covered by the manufacturer even with the utilizing of internet. Distribution channels handle a number of functions such functions have to be divided between the manufacturer and the members of the distribution intermediaries in an efficient and effective ways. These functions have to satisfy the market demand and create customer value by providing fast delivery and enhanced services at acceptable prices. Kotler, Armstrong, Tolba, and Habib (2012) summarized the distribution channel functions in the following eight main dimensions:

1) Physical Distribution: This is the main goal of distribution channel which include the planning, executing, managing, and regulating the steps of making the products and services available to the end-users in the right time at the right place.

2) Financing: Acquiring and using funds to cover the costs of the channel work.

3) Risk Taking: Assuming the risks of carrying out the channel work.

4) Promotion: Developing and spreading persuasive communications about an offer.

5) Matching: Shaping and fitting the offer to the buyer's needs, including activities such as manufacturing, grading, assembling, and packaging.

6) Negotiation: Reaching an agreement on price and other terms of the offer so that ownership or possession can be transferred.

7) Contact: Finding and communicating with prospective buyers.

8) Gathering Information: Gathering and distributing marketing research and intelligence.

The question is not whether these functions need to be performed - they must be - but rather who will perform them and how. Internet usage could be part of the answer; it could help handle some of these functions directly leading to reduce the number of intermediaries firms have to deal with. Also it could help assigning the functions of the distribution channels in more effective way allowing the manufacturer to have more control over the products flow, but might as well create conflicts with other distribution channels. Nevertheless, a string connection is clearly established between internet usage and distribution channels. 


\subsection{Internet Usage and Distribution Channels}

Internet can be described as worldwide electronic directory (yellow pages) where users or browser can find information regarding products' supporting services or business contact details (Anderson, 1996; Himmelstein, 2005). It was predicted that internet would eliminate the use of dealers and intermediaries for certain product types (Morgansky, 1997). Today this notion can be proven with the unlimited number of digital products that are transferred (delivered) directly from the manufacturer to the end-users through internet.

The Internet is challenging the traditional distribution structures of firms in almost every industry; coercing firms to reassess their value proposition to end-users, and meet the challenges of more competitive world (Ghosh, 1998; Rao, 1999; Hultkrantz \& Lumsden, 2001; Hultkrantz \& Stahre, 2005; Buhalis \& Kaldis, 2008). Hence, Internet as a direct channel presents a good substitute for traditional distribution channels. Pitt et al. (1999) discussed the effect of internet on distribution strategies thoroughly and joined many other scholars in this orientation (Rao, 1999; Henderson et al., 2001; King et al., 2002). However, it should be clear that intermediaries (and dealers) perform different activities that are not easily replaced by manufacturers, at least not with the current structure of supply chain and distribution channels, such activities would include but not limited to: holding immediately available inventory, providing variety that make one-stop shopping possible, providing several forms of services including personal assistance, facilities, repair services, and return services (Levy \& Weitz, 2004). These activities cannot be totally provided by the manufacturers' internet direct channels alone especially that consumers are not all online shoppers and traditional consumer would still require face to face interaction with sellers. Accordingly, apart from the distribution of digital products, internet probably will face hard challenges eliminating the traditional distribution channels completely (Peterson et al., 1997; Mehra, 1999; Law et al., 2004; Goldkuhl, 2005; Broekhuizen, 2006; Molenaar, 2009). Thus, in most cases and up to this moment, many firms add internet distribution to its already existing distribution channels, but didn't eliminate or reduce intermediaries.

Whether internet replaced the traditional distribution channels or just altered them, researchers from different orientations agreed that internet has an effect on traditional distribution channels; this research is trying to understand the nature of this effect in Jordanian firms. The effect of internet usage on traditional distribution channels will be measured in two aspects: creating a new direct online distribution channel and reducing the number of intermediaries.

It should be clear that the above mentioned discussion does not cover virtual firms, since by definition, these firms imply a high degree of telecommuting and operate in untraditional ways, and normally depend on internet as the main or perhaps the only distribution and communication channel.

\subsection{Firm's Size}

Firms vary in sizes and normally each size will reflect a certain assets and manpower. The effect of firm's size on the relationship between internet usage and traditional distribution channels will be examined in this study to explore the possible moderating effect of the size on the relationship between the main variables (independent and dependent).

In Jordan, the main classification criteria for private commercial firms sizes is the registered capital, according to the Jordanian Ministry of Industry and Trade records, private firms can be classified into: Small Private firms with registered capital less than 24, 999 JD (less than 34999 USD), Medium Private Firms with registered capital between 25000 JD and 49, 999 JD (35 000 to 69999 USD), and Large Private Firms with registered capital of $50000 \mathrm{JD}$ and more (70 $000 \mathrm{USD}$ and more). It should be clear that neither this classification nor this study cover the shareholding firms (public or private), as it is aimed at private commercial firms in Jordan only.

A full list of commercial firms was obtained from Amman Chamber of Commerce for the three main classifications representing the population of interest in this study; further information about this is presented in section 4.2 .

\section{Research Model and Hypotheses}

The research model was developed based on the literature review, the hypothesized model consisted of three main variables: the independent variable (Internet Usage), the dependent variable (Traditional Distribution Channels), and the moderating variable (Firm's Size) as shown in Figure 1 below. 


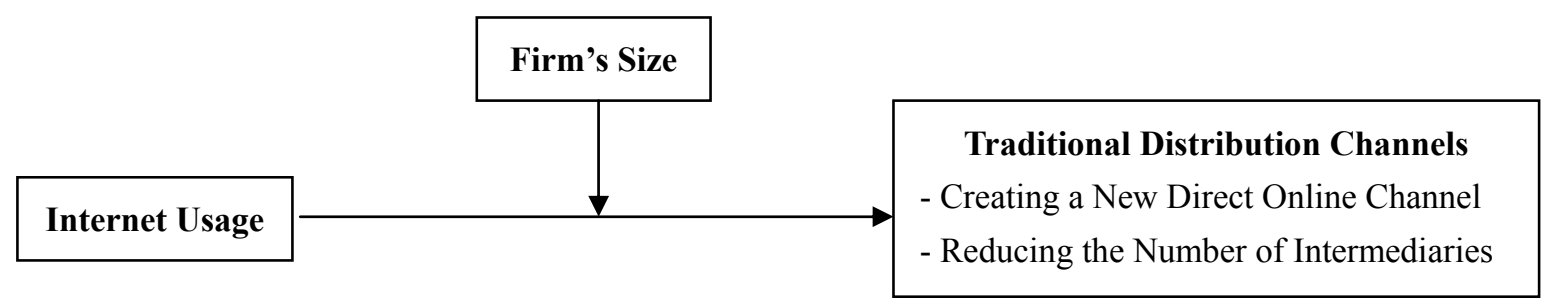

Figure 1. Study model

\subsection{The First Hypothesis}

H01: Internet Usage has a direct effect on Traditional Distribution Channels at $(\alpha>0.05)$ significance level.

This hypothesis will be measured through the following sub-hypotheses:

H01.1 Internet Usage has created a new direct online channel at $(\alpha>0.05)$ significance level.

H01.2 Internet Usage has reduced the number of intermediaries at $(\alpha>0.05)$ significance level.

\subsection{The Second Hypothesis}

H02: The relationship between Internet Usage and Traditional Distribution Channels will be moderated by the firm's size at $(\alpha>0.05)$ significance level.

\section{Study Methodology}

This research is trying to recognize the effect of the independent variable on the dependent variable; therefore it is a causal research. Quantitative approach was considered more compatible with the goal of this study. Since this study is without any control on the conducts of the respondents, survey strategy was utilized. This research is inductive research since it depends on the empirical findings.

Questionnaire was developed and used to gather data from the respondents; the questionnaire consisted of three parts as follows:

1- Part one (demographic information): included the personal and occupational information of the study individuals: age, educational level, gender, professional experience, current position and firm's size.

2- Part two gathered data on the independent variable (internet usage), the actual utilization of internet in the firms, after checking for an active website and valid e-mail addresses.

3- Part Three gathered data on the dependent variable (traditional distribution channels). The questionnaire's statements in this part were centered on two main aspects: the creating of a new direct channel and reducing the intermediaries in the traditional distribution channels. The statements revolved around the main destruction channels functions mentioned in section 2.1.

Part two and three were five-point Likert scale, ranging from (strongly disagree) to (strongly agree).

The collected data were analyzed using the statistical package for the social sciences (SPSS).

\subsection{Validity and Reliability}

Both face validity and content validity were established by presenting the research tool to panel of experts and to randomly selected group of respondents.

The reliability of this study constructs was evaluated by Cronbach Alpha Coefficient (Sekaran, 2003). The limit was set at 0.70 (Nunnaly, 1978) any values higher than this cutoff limit are considered reliable measures. The results are presented in Table 1 below.

Table 1. Cronbach alpha coefficient

\begin{tabular}{ccc}
\hline Domain & Number of Items & Cornbach Alpha Value \\
\hline Distribution Channels & 18 & 0.892 \\
Internet Usage & 16 & 0.946 \\
All Questionnaire & 34 & 0.934 \\
\hline
\end{tabular}


Table 1 shows the reliability test for the study constructs, the results shows that the measures of both domains are reliable; the overall questionnaire reliability is 0.934 indicating a high level of reliability.

\subsection{Study Population and Sample}

The study population was specified as the top and middle management of Jordanian private commercial firms. The firm must have both an active website and valid e-mail address to be considered within the study population, as it will be pointless to gather data from firms that do not use internet for this study.

Jordan is relatively a small country and the majority of private commercial firms are positioned in the capital city of Amman; therefore, the researchers restricted the sampling framework to the top and middle management of firms located in Amman. The principal selection factor was the registered capital acquired from Jordanian Ministry of Industry and Trade. The private commercial firms in Jordan can be classified into small, medium, and large firms; therefore, a proportional stratified random sampling method was applied to choose a representative sample using a systematic sampling technique on the list of firms obtained from Amman Chamber of Commerce (the targeted population). This process achieved the same result as simple random sampling method but with additional competence (Burns \& Bush, 1998).

After completing the sampling process, a list of 279 firms were selected; each firm had to fill four copies of the questionnaire, two copies by top management who is responsible of the strategic and vital decisions in the firm, and the two by middle management aimed at sales \& marketing and supply chain managers, in small private firms and some medium firms such positions do not exists independently, in such cases the questionnaire was filled by the person who most fit the job description of these positions but without duplication. On the other hand, in some large firms the marketing \& sales are two separate positions (as it should be) in such cases three questionnaires were filled by the marketing, sales, and supply chain mangers. The total number of distributed questionnaires was 1150; the final number of recovered, filtered, and screened questionnaire was 904, with response rate of $79 \%$ of the total distributed copies.

\section{Presentation and Analysis of Data}

\subsection{Sample Characteristics}

The study sample characteristics are demonstrated in Table 2 below.

Table 2. Study sample characteristics

\begin{tabular}{lll}
\hline Variables & Category & Frequency \\
\hline Age & $18-29$ & 134 \\
& $30-39$ & 188 \\
& $40-49$ & 444 \\
Educational Level & 50 and above & 138 \\
& Total & $\mathbf{9 0 4}$ \\
& diploma or less & 176 \\
& Bachelor degree & 536 \\
Post graduate & 192 \\
Total & $\mathbf{9 0 4}$ \\
Males & 772 \\
Professional Experience & Females & 132 \\
& Total & $\mathbf{9 0 4}$ \\
$1-6$ years & 118 \\
& 7 - 12 years & 134 \\
$13-18$ years & 200 \\
$19-24$ years & 356 \\
25 years and more & 96 \\
& Total & $\mathbf{9 0 4}$ \\
\hline
\end{tabular}




\begin{tabular}{lll}
\hline Firm's Size* & Small Firms & 180 \\
& Medium Firms & 480 \\
Large Firms & 244 \\
Total & $\mathbf{9 0 4}$ \\
\hline
\end{tabular}

* Based on the registered capital.

\subsection{Descriptive Results}

Means, Standard Deviation (SD), Percentages of Maximum Respond Scale (out of 5), and Skewness for variables are presented in Table 3.

Table 3. Descriptive statics

\begin{tabular}{llllll}
\hline & \multicolumn{1}{c}{ Items } & Mean & SD & Skewness & \\
\hline 1 & Traditional Distribution Channels & 3.62 & 0.55 & 78.70 & -1.12 \\
2 & Internet Usage & 3.84 & 0.59 & 80.60 & -1.91 \\
\hline
\end{tabular}

Table 3 indicates the results of Means, SD, and Percentages for each domain, the table also indicates the normality of data distribution; the values of skewness indicate a normal distribution of the data concerning each domain. The normal critical values considered are -3 to +3 (Huzaifah, 2002, cited by Dubauskas \& Teresienè, 2005).

\subsection{Hypotheses Testing}

This study is founded on two main hypotheses; below are the results the hypotheses testing.

\subsubsection{The First Hypothesis}

H01: Internet Usage has a direct effect on Traditional Distribution Channels at $(\alpha>0.05)$ significance level.

This hypothesis is tested through the following sub-hypotheses

H01.1 Internet Usage has created a new direct online channel at $(\alpha>0.05)$ significance level.

H01.2 Internet Usage has reduced the number of intermediaries at $(\alpha>0.05)$ significance level.

\subsubsection{The First Sub-Hypothesis}

Table 4 demonstrates the simple liner regression analysis for: internet usage on creating a new direct online channel.

Table 4. Simple linear regression analysis for internet usage on creating new direct online channel

\begin{tabular}{|c|c|c|c|c|c|c|c|c|c|c|}
\hline Component & $\mathrm{R}^{2}$ & $\mathrm{f}$ & $\operatorname{Sig} \mathrm{f}$ & $\mathrm{t}$ & Sig $\mathrm{t}$ & $\alpha$ & Constant & $\beta$ & Coefficient & Decision \\
\hline Internet Usage & .223 & 73.18 & 0.00 & 8.55 & 0.000 & & 2.100 & & 0.499 & Accept \\
\hline
\end{tabular}

Critical $f$ at 0.05 level $=3.89$ (degree of freedom $1 \& 251)$.

Table 4 shows the results of simple linear regression analysis for the relationship between internet usage and creating new direct online channel. $f$ value is higher than the critical $f$ indicating a significant positive relationship between internet usage and creating new direct online channels. The relative importance of this significant relationship can be evaluated through $\mathrm{R}^{2} ; \mathrm{R}^{2}$ value is 0.223 suggesting a weak contribution to the traditional distribution channels. The $\mathrm{t}$ statistic proves the existence of a linear relationship between internet usage and traditional distribution channels, as t value was significant (sig value is less than 0.05) showing an importance of internet usage on traditional creating new direct online channels, this importance is quantified by the value of $\mathrm{R}^{2}$.

Based on the results of Table 4; the first sub-hypothesis (H01.1) is accepted. 


\subsubsection{The Second Sub-Hypothesis}

Table 5 demonstrates the simple liner regression analysis for: internet usage has reduced the number of intermediaries.

Table 5. Simple linear regression analysis for internet usage on reducing the number of intermediaries

\begin{tabular}{lrrrrrrrrrr}
\hline Component & $\mathrm{R}^{2}$ & $\mathrm{f}$ & $\operatorname{Sig~} \mathrm{f}$ & $\mathrm{t}$ & $\operatorname{Sig~t}$ & $\alpha$ & Constant & $\beta$ & Coefficient & Decision \\
\hline Internet Usage & .038 & 2.59 & 0.056 & 1.61 & 0.056 & 2.130 & 0.318 & Reject \\
\hline
\end{tabular}

Critical $\mathrm{f}$ at 0.05 level $=3.89($ degree of freedom $1 \& 251)$.

Table 5 shows the results of simple linear regression analysis for the relationship between internet usage and reducing the number of intermediaries. $f$ value is lower than the critical $f$, this indicates a none significant relationship between internet usage and reducing the number of intermediaries.. The $t$ statistic proves that there is no linear relationship between internet usage and reducing the number of intermediaries, as $t$ value was none significant (sig value is higher than 0.05 ).

Based on the results of Table 5; the second sub-hypothesis (H0.1.2) is rejected.

\subsubsection{The First Hypothesis Decision}

Based on sections 5.3.1 and 5.3.2 the first hypothesis of the study (H01: Internet Usage has a positive direct effect on Traditional Distribution Channels at $(\alpha>0.05)$ significance level) is partly accepted, since it was measured through two sub-hypotheses, one was accepted and the other was rejected.

\subsubsection{The Second Hypothesis}

H02: Firm's Size affects the relationship between Internet Usage and Distribution Channels at $(\alpha>0.05)$ significance level.

The firm's size was classified as small, medium, and large firms, Table 6 demonstrates the simple liner regression analysis for Firm's Size effect on internet usage and distribution channels.

Table 6. Simple linear regression for firm's size moderating effect

\begin{tabular}{cccccccc}
\hline Firm's Size & $\mathrm{R}^{2}$ & Critical $\mathrm{f}$ & $\mathrm{f}$ & $\mathrm{Sig} \mathrm{f}$ & $\mathrm{t}$ & $\mathrm{Sig} \mathrm{t}$ & Decision \\
\hline Large & 0.411 & $4.39(1 \& 17)$ & 26.86 & 0.001 & 5.18 & 0.001 & Accept \\
Medium & 0.265 & $3.90(1 \& 179)$ & 61.11 & 0.000 & 7.82 & 0.000 & Accept \\
Small & 0.101 & $4.30(1 \& 21)$ & 11.48 & 0.004 & 3.39 & 0.004 & Accept \\
\hline
\end{tabular}

For large firms, $f$ value exceeds the critical $\mathrm{f}$ value indicating significant relationship. The value of $\mathrm{R}^{2}$ (amounting 0.411) Suggests moderate relative importance of internet usage on traditional distribution channels in large private commercial firms.

As for the medium firms, $\mathrm{f}$ value exceeds the critical $\mathrm{f}$ value indicating significant relationships. The value of $\mathrm{R}^{2}$ (amounting 0.265) suggests a weak relative importance of internet usage on traditional distribution channels in medium size private commercial firms.

For Small firms, $f$ value also exceeds the critical $f$ value indicating a significant relationship. The value of $\mathrm{R}^{2}$ (amounting 0.101) suggests weak relative importance of internet usage on traditional distribution channels in small private commercial firms. $\mathrm{R}^{2}$ value for small firms is the lowest among the three sizes.

All $\mathrm{t}$ values were found to be significant $(\mathrm{sig}<0.05)$ suggesting linear relationship between internet usage and traditional distribution channels for all three firm sizes.

Table 7 below demonstrates stepwise multiple regression results for firm's size effect on the relation between internet usage and traditional distribution channels. 
Table 7. Stepwise multiple regression results for firm's size effect

\begin{tabular}{lcccccccc}
\hline Firm's Size & $\mathrm{R}^{2}$ & Critical f & $\mathrm{f}$ & Sig f & $\mathrm{t}$ & Sig t & $\beta$ coefficient & $\alpha$ constant \\
\hline Large & 0.411 & $4.39(1 \& 17)$ & 26.86 & 0.001 & 5.18 & 0.001 & 0.801 & 0.367 \\
\hline
\end{tabular}

Upon the data in table (7) a prediction model can be constructed as follows:

Traditional Distribution channels $=0.801 *$ Internet Usage +0.367 .

\section{Conclusions and Recommendations}

\subsection{Conclusions}

Based on the finding in section 5, the first hypothesis was partly accepted indicating that internet usage has partly direct effect on traditional distribution channels this effect is limited to creating new direct online channel. The second hypothesis was accepted indicating that firms' size affects the relationship between internet usage and traditional distribution channels.

These results mean that internet usage did not reduce the number of intermediaries firms have to deal with. In other words, the current internet usage did not substitute the tasks normally carried out by intermediaries on any level and therefore the Jordanian private commercial firms still need all the intermediaries it deal with, although this is consistent with previous studies found in the literature review (Peterson et al., 1997; Mehra, 1999; Law et al., 2004; Goldkuhl, 2005) things were expected to developed as we enter year 2014 and internet become more and more an essential part of the daily life. The results also indicate that internet usage in some Jordanian firms has created a new direct online channel, but in general the effect of internet usage on creating new direct online channel is relatively weak (as demonstrated in Table 5). Jordanian private commercial firms are not utilizing the internet capabilities as a distribution channel; it is mainly used for distribution of information and not to provide products to the end-users directly, it is also used as a sort of logistic support especially in the communication filed where internet usage can provide better communication platform. Customers may have played a role in these results, since the majority of internet users in Jordan are uncertain when it comes to online ordering and delivery. Jordan has one of the fastest internet adoption rates in the area, internet penetration in Jordan reached $63 \%$ by the end of September 2012 (Equities, 2012) compared to 50.5\% by the end of 2011 (Ghazal, 2012). Internet usage more than doubled from 2007 to 2009, but users still face some security issues when ordering online, these results and conclusion are consistent with local previous studies revolve around the same concept (Albarq, 2000; Asoub, 2006; Akroush, et al., 2009; Khasawneh et al., 2009) and apparently the situation in Jordanian firms did not actually change in a significant way. As for the moderation effect of firm's size and although the hypothesis was accepted, medium and small firms sizes have a weak moderating effect on the internet usage and traditional distribution channels, while only large firm showed mild moderating effect of its size on the internet usage and traditional distribution channels indicating that the firm's size has acutely affected the relation between the independent variable (internet usage) and dependent variable (traditional distribution channels). The larger the firm is, the higher the internet usage effect traditional distribution channels. This could be explained by the fact that larger firm's will normally have more capabilities, resources, and assets to invest in applying new channels and utilizing new tools. Moreover, larger firms normally operate through structured managerial and administrative systems that might make it easier to apply and monitor the performance of such new channel.

\subsection{Recommendations}

In the light of the above, the researchers suggest that Jordanian commercial firms should evaluate the benefits and gains of internet usage on distribution channels. It is true that the current effect of internet usage on distribution channels partly exist but it is not as deep or as wide as it should be compared to similar situation in developed countries. Government and international development agencies should educate the local firms about the great opportunities of internet usage in general and in distribution in particular. These efforts should be directed mainly to medium and small firms, as many studies reviled the benefits of internet usage to small and medium enterprises (SMEs) worldwide, in Jordan, such firms may not be aware of the great benefit of internet usage or not willing to handle the risk of internet investment especially in the hard economical situation most countries face after the world credit crunch. The best way to overcome these problems is by educating the firms and showing them how to do it right; training courses, seminars, and workshops are necessary to explain the potential of internet usage in commercial firms, following up measures are highly needed to enhance the performance of Jordanian firms and accordingly the whole Jordanian economy. On the other hand, the 
government and officials should have the right measures and laws to enhance the trust of Jordanian consumers in online transaction, which should encourage firms to expand internet usage on so many levels including the online direct distribution.

As for future researches, the researchers recommend testing the same model in other developing countries to compare the results, testing the same model on other sectors locally and in the region. Examining other moderating effect could be a good area for future researches. In a later stage, examining the internet usage effect on other marketing strategies, activities and practices could lead to more comprehensive picture of the actual effect on internet on marketing in Jordan and other developing countries.

\section{References}

Akroush, M., Nuseir, M., Asoub, A., \& Mahadin, B. (2006). The Relationship between the e-Marketing Mix Strategies and Organizational Performance: an Empirical Investigation of International Organizations in Jordan. International Journal of Electronic Marketing and Retailing, 2(4), 317-351. http://dx.doi.org/10.1504/IJEMR.2009.025248

Albarq, A. (2000). Intention to Shop Online Among University Students in Jordan. University Utara Malaysia.

Aldridge, A., Forcht, K., \& Pierson, J. (1997). Get linked or get lost: marketing strategy for the Internet. Internet Research, 7(3), 161-169. http://dx.doi.org/10.1108/10662249710171805

Anderson, E. (1985). The salesperson as outside dealer or employee: a transaction cost analysis. Journal of Marketing Science, 4(3), 234-254. http://dx.doi.org/10.1287/mksc.4.3.234

Anderson, R. E. (1996). Personal Selling and Sales Management in the New Millennium. Journal of Personal Selling and Sales Management, 16(4), 17-32.

Asoub, A. (2006). The Role of E-Marketing and its Effects on International Trade: Application Study on Trading Companies in Jordan. Faculty of Graduate Studies, University of Jordan, October, 2006.

Broekhuizen, T. (2006). Understanding Channel Purchase Intentions: Measuring Online and Offline Value Perceptions. MSc thesis, Rijksuniversiteit Groningen, Groningen, Netherland.

Bucklin, L. P. (1966). A Theory of Distribution Channel Structure. Berkeley, CA: IBER Special Publications.

Buhalis, D., \& Kaldis, K. (2008). Enabled Internet Distribution for Small and Medium Sized Hotels. Tourism Recreation Research, 33(1), 1-15.

Burns, A. C., \& Bush, R. F. (1998). Marketing Research (3rd ed.). New Jersey: Prentice Hall International, Inc.

Cockburn, C., \& Wilson, T. (1996). Business use of the World-wide Web. International Journal of Information Management, 16(2), 83-102. http://dx.doi.org/10.1016/0268-4012(95)00071-2

Coffman, K. G., \& Odlyzko, A. M. (2001). Growth of the Internet. AT\&T Labs-Research.

Dent, J. (2008). Distribution Channels: Understanding and Managing Channels to Market. Kogan Page Ltd.

Dubauskas, G., \& Teresienè, D. (2012). Autoregressive Conditional Skewness, Kurtosis and Jarque-bera in Lithuanian Stock Market Measurement. Engineering Economics, 5(45), 19-24.

Equities (2012). Mobile broadband speeds surpass regional average.

Ghazal, M. (2012, March, 6). E-government services can help increase Internet penetration. The Jordan Times.

Ghosh, S. (1998, March). Making business sense of the Internet. Harvard Business Review.

Goldkuhl, L. (2005). Multiple Marketing Channel Conflict with a Focus on the Internet. PhD thesis, Luleå: Luleå University of Technology.

Griffiths, R. (1999). Internet for Historians, History of the Internet. The development of the Internet. Retrieved from http://www.let.leidenuniv.nl/history/ivh/INTERNET.HTM

Henderson, R. J., Dooley, F., Akridge, J., \& Boehlje, M. (2001). E-Business and Distribution Channel Strategies in Agribusiness Industries. Paper Presented at the American Agricultural Economics Association Meetings, August 5-8, 2001.

Himmelstein, M. (2005). Local Search: The Internet is the Yellow Pages. Long Hill Consulting, IEEE Computer Society. http://dx.doi.org/10.1109/MC.2005.65

Hultkrantz, O., \& Lumsden, K. (2001). E-commerce and Consequences for the Logistics Industry. Seminar on the Impact of E-Commerce on Transport, Paris. 
Hultkrantz, O., \& Stahre, F. (2005). Analyzing the Potential for Direct Deliveries. Proceedings of the 10th International Symposium on Logistics "Innovations in Global Supply Chain Networks", 2005.

Khasawneh, A., Al Azzam, I., \& Bsoul, M. (2009). A Study on e-Commerce Security in Jordan. International Journal of Electronic Finance, 3(2), 166-176. http://dx.doi.org/10.1504/IJEF.2009.026358

King, R. C., Sen, R., \& Xia, M. (2002). Impact of Web-based E-Commerce on Channel Strategy. Working Paper, The University of Illinois at Urbana.

Kotler, P., Armstrong, G., Tolba, A., \& Habib, A. (2012). Principles of Marketing Arab World Edition. Pearson Education Limited.

Law, R., Leung, K., \& Wong, J. (2004). The impact of the Internet on travel agencies. International Journal of Contemporary Hospitality Management, 16(2), 100-107. http://dx.doi.org/10.1108/09596110410519982

Levy, M., \& Weitz, B. A. (2004). Retailing Management (5th ed.). Boston, Mass: McGraw-Hill Irwin.

Mehra, A. (1999). Impact of Internet on Intermediaries. Master Thesis, Massachusetts Institute of Technology.

Melewar, T. C., \& Smith, N. (2003). The Internet Revolution: Some Global Marketing Implications. Marketing Intelligence \& Planning, 21(6), 363-369. http://dx.doi.org/10.1108/02634500310499220

Michelle, M. A. (1997). Retailing and the Internet. International Journal of Retail and Distribution Management, 25(1), 372-377. http://dx.doi.org/10.1108/09590559710192477

Molenaar, C. (2009). Het Nieuwe Winkelen. Amsterdam: Prentice Education.

Nath, R., Akmanligil, M., Hjelm, K., Sakaguehi, T., \& Schultz, M. (1998). Electronic commerce and the Internet: issues, problems, and perspectives. International Journal of Information Management, 18(2), 91-101. http://dx.doi.org/10.1016/S0268-4012(97)00051-0

Nunnaly, J. (1978). Psychometric theory. New York: McGraw-Hill.

Perreault, W. D., Cannon, J. P., \& McCarthy, E. J. (2008). Basic Marketing: A Marketing Strategy Planning Approach (17th ed.). McGraw-Hill.

Peterson, R. A., Balasubramanian, S., \& Bronnenberg, B. J. (1997). Exploring the Implications of the Internet for Consumer Marketing. Journal of the Academy of Marketing Science, 25(4), 329-346. http://dx.doi.org/10.1177/0092070397254005

Pitt, L. F., Berthon, P., \& Berthon, J.-P. (1999). Changing Channels: The Impact of the Internet on Distribution Strategy. Business Horizons, 42(2), 19-28. http://dx.doi.org/10.1016/S0007-6813(99)80005-6

Rao, B. (1999). The Internet and the revolution in distribution: a cross-industry examination. Technology in Society, 21, 287-306. http://dx.doi.org/10.1016/S0160-791X(99)00018-4

Scupola, A. (2002). Adoption Issues of Business-to-Business Internet Commerce in European SMEs. Paper presented at the 35th Annual International Conference on System Sciences, Hawaii. 2002. http://dx.doi.org/10.1109/HICSS.2002.994141

Sekaran, U. (2003). Research Methods for Business, A Skill Building Approach (4th ed.). NY: John Wiley \& Sons Inc.

Strauss, J., \& Frost, R. (2012). E-marketing (6th ed.). Pearson USA International Edition.

Wen, H. J., Chen, H., \& Hwang, H. (2001). E-commerce Web site design: strategies and models. Information Management \& Computer Security, 9(1), 5-12. http://dx.doi.org/10.1108/09685220110366713

Yoffie, B. D. (2010). Innovation Changing the World: New Technologies. Paper presented at Harvard and China: A Research Symposium conference, Mar. 18, 2010.

\section{Copyrights}

Copyright for this article is retained by the author(s), with first publication rights granted to the journal.

This is an open-access article distributed under the terms and conditions of the Creative Commons Attribution license (http://creativecommons.org/licenses/by/3.0/). 